\title{
Right Ventricular Wall
}

National Cancer Institute

\section{Source}

National Cancer Institute. Right Ventricular Wall. NCI Thesaurus. Code C127649.

The wall of the right ventricle, comprising anterior, inferior, and lateral walls; and excluding the interventricular septum. 